удк 343.4

Е. Г. Усов

Восточно-Сибирский институт МВД России, г. Иркутск, Российская Федерация

\title{
К ВОПРОСУ О КВАЛИФИКАЦИИ ПРЕСТУПЛЕНИЯ, ПРЕДУСМОТРЕННОГО СТ. 138.1 УК РФ
}

\begin{abstract}
АНнотАция. Уголовно-правовое регулирование оборота специальных технических средств для негласного получения информации в современных условиях приобретает все большую актуальность. Вместе с тем, указанная сфера общественных отношений нуждается в законодательной доработке. До сих пор остается открытым вопрос об определении предмета преступления. Объективная сторона преступления представлена неполным набором альтернативных действий, кроме того отсутствует единый подход к их толкованию. В частности, на данный момент нет единого мнения относительно соотношения понятий «изготовление» и «производство» специальных технических средств для негласного получения информации. В статье автором дана оценка существующим критериям отнесения технических средств к категории специальной техники для негласного получения информации, озвучены существующие в уголовно-правовой доктрине подходы $\kappa$ пониманию термина «производство», выдвинуты предложения по совершенствованию действующего законодательства в сфере оборота специальной техники.

кЛючЕВЫЕ слОВА. Незаконный оборот; специальные технические средства; негласное получение информации; информация; теории информации; информационное взаимодействие; виды и свойства информации; информационный ресурс. ИНФОРМАЦИЯ О СТАТЬЕ. Дата поступления 8 мая 2017 г.; дата принятия к печати 19 марта 2018 г.; дата онлайн-размещения 09 апреля 2018 г.
\end{abstract}

E. G. Usov

East-Siberian Institute of the MIA of Russia, Irkutsk, Russian Federation

\section{ON THE ISSUE OF CRIME QUALIFICATION UNDER ART. 138.1 OF THE CRIMINAL CODE OF THE RUSSIAN FEDERATION}

ABSTRACT. Criminal-legal regulation of turnover of the special technical means for a surreptitious obtaining of information in modern terms is becoming more important. At the same time, this sphere of social relations needs a legislative improvement. The issue of assessing the crime subject remains open until now. The objective side of a crime is represented by incomplete set of alternative actions, besides there is no uniform approach to their interpretation. In particular, at the moment there is no consensus on the correlation between the concepts of «manufacturing" and "production» of special technical means for a surreptitious obtaining of information. The author assesses the existing criteria of classifying the technical equipment as a special technique for surreptitious obtaining of information, presents the approaches existing in the criminal legal doctrine to understand the term "production", and offers to improve the current legislation in the sphere of the special equipment turnover.

KEYWORDS. Illegal trafficking; special technical means; surreptitious obtaining of information; information; information theories; information interaction; types and properties of information; information resource.

ARTICLE INFO. Received May 8, 2017; accepted March 19, 2018; available online April $09,2018$.

\section{Baikal Research Journal}

электронный научный журнал Байкальского государственного университета 
Тема правового регулирования оборота специальных технических средств для негласного получения информации (далее - СТС НПИ) получила достаточно широкое освещение в средствах массовой информации в связи с появлением большого количества вступивших в законную силу приговоров суда. Имеющиеся законодательные пробелы отчасти обусловили тот негатив, с которым широкая общественность относится к уголовной ответственности за незаконный оборот специальных технических средств для негласного получения информации. Высокие технологии стали неотъемлемой частью нашей жизни, вопросы предупреждения преступлений, предусмотренных ст. 138.1 УК РФ являются на сегодняшний день достаточно актуальными и вызывают к себе повышенный интерес законодателя [1].

Родовой объект преступления, предусмотренного ст. 138.1 УК РФ представлен общественными отношениями, возникающими в связи с реализацией прав личности. Видовым объектом данного преступления, выступают общественные отношения в сфере реализации конституционных прав и свобод человека и гражданина. Однако касаемо непосредственного объекта в уголовно-правовой доктрине существует несколько разнонаправленных точек зрения. До изменений, внесенных в УК РФ в 2011 году, в ч. 3 ст. 138 УК РФ, существовало две точки зрения: одни авторы относили ч. 3 к особо квалифицирующим признакам ст. 138 , другие считали, что в ч. 3 содержатся признаки самостоятельного состава [2, с. 118]. Соответственно, и подход к определению непосредственного объекта был различный. Так, приверженцы первой точки зрения в качестве непосредственного основного объекта рассматривали общественные отношения, охраняющие право человека и гражданина на тайну переписки, телефонных переговоров, почтовых, телеграфных или иных сообщений, а общественные отношения, охраняющие регулирование государством оборота специальных технических средств, предназначенных для негласного получения информации, - в качестве дополнительного объекта [3, с. 84]; сторонники самостоятельного состава - установленный законодательством порядок производства и оборота специальных технических средств, предназначенных для негласного получения информации [4; 5]. По мнению Н. В. Подгорной, непосредственным объектом данного преступления является установленный законодательством порядок производства, и оборота специальных технических средств соответствующей категории [6]. Существуют и другие точки зрения, в частности, Т. Устинова считает незаконный оборот СТС НПИ одним из видов незаконной предпринимательской деятельности [7]. В. А. Новиков полагает, что незаконный оборот СТС НПИ посягает на основы конституционного строя и безопасности государства [8]. Родивилин И. П. и Родивилина В. А. считают, что уголовная ответственность за незаконный оборот СТС НПИ должна наступать в том случае, если лицо намеревалось использовать данное устройство для незаконного собирания информации, в противном случае вред объекту уголовно-правовой охраны не наносится и содеянное надлежит квалифицировать как административное правонарушение [9].

Предмет указанного состава преступления является, пожалуй, наиболее обсуждаемым элементом состава преступления. Четкого легального определения СТC НПИ нет [10]. Стоит отметить, что отсутствие законодательного определения СТС НПИ привело к тому, что и среди специалистов в области уголовного права нет единого мнения по поводу того, что стоит отнести к СТС НПИ [11].

В Положении о лицензировании деятельности по выявлению электронных устройств, предназначенных для негласного получения информации (за исключением случая, если указанная деятельность осуществляется для обеспечения собственных нужд юридического лица или индивидуального предпринимателя) имеется определение понятия электронное устройство, предназначенное для

\section{Baikal Research Journal}


негласного получения инфорлации - специально изготовленное изделие, содержащее электронные компоненты, скрытно внедряемое (закладываемое или вносимое) в места возможного съема защищаемой акустической речевой, визуальной или обрабатываемой информации (в том числе в ограждения помещений, их конструкции, оборудование, предметы интерьера, а также в салоны транспортных средств, в технические средства и системы обработки информации) ${ }^{1}$. Однако, указанное определение более узким, нежели понятие «специальное техническое средство для негласного получения информации», так как наличие электронной составляющей не является обязательным для СТС НПИ, могут использоваться другие принципы работы (например, механический принцип работы некоторых фотоаппаратов). Кроме того, формулировка «скрытно внедряемое (закладываемое или вносимое)» не очень удачно подходит для ст. 138.1 УК РФ, так как в случаях сбыта или приобретения СТС НПИ доказывать факт скрытного внедрения не нужно.

В настоящее время существует Перечень видов специальных технических средств, предназначенных (разработанных, приспособленных, запрограммированных) для негласного получения информации в процессе осуществления оперативно-розыскной деятельности. Данный перечень утвержден постановлением Правительства РФ «Об утверждении Положения о лицензировании деятельности физических и юридических лиц, не уполномоченных на осуществление оперативно-розыскной деятельности, связанной с разработкой, производством, реализацией, приобретением в целях продажи, ввоза в Российскую Федерацию и вывоза за ее пределы специальных технических средств, предназначенных (разработанных, приспособленных, запрограммированных) для негласного получения информации, и Перечня видов специальных технических средств, предназначенных (разработанных, приспособленных, запрограммированных) для негласного получения информации в процессе осуществления оперативно-розыскной деятельности» от 01 июля 1996 г. № 770. Перечень включает в себя следующие группы специальных технических средств:

1. Специальные технические средства для негласного получения и регистрации акустической информации;

2. Специальные технические средства для негласного визуального наблюдения и документирования;

3. Специальные технические средства для негласного прослушивания телефонных переговоров;

4. Специальные технические средства для негласного перехвата и регистрации информации с технических каналов связи.

5. Специальные технические средства для негласного контроля почтовых сообщений и отправлений;

6. Специальные технические средства для негласного исследования предметов и документов;

7. Специальные технические средства для негласного проникновения и обследования помещений, транспортных средств и других объектов;

8. Специальные технические средства для негласного контроля за перемещением транспортных средств и других объектов;

1 Об утверждении Положения о лицензировании деятельности по выявлению электронных устройств, предназначенных для негласного получения информации (за исключением случая, если указанная деятельность осуществляется для обеспечения собственных нужд юридического лица или индивидуального предпринимателя) : постановление Правительства РФ от 16.04.2012 г. № 314 г. // С3 РФ. 2012. № 17. Ст. 1988.

\section{Baikal Research Journal}


9. Специальные технические средства для негласного получения (изменения, уничтожения) информации с технических средств ее хранения, обработки и передачи;

10. Специальные технические средства для негласной идентификации личности.

Однако указанный перечень дает только общее представление о предмете преступления, предусмотренного ст. 138.1 УК РФ. Для того чтобы четко определить объем и содержание понятия «Специальные технические средства для негласного получения информации» недостаточно перечисления родовых признаков частных случаев указанного понятия. Неопределенность предмета представляется наибольшей проблемой, препятствующей правильной квалификации деяния и отграничения преступления от правомерного деяния.

Необходимо отметить, что ряд технических устройств при условии их использования по прямому назначению (например, радионяни для контроля за ребенком) не представляют общественной опасности, они являются естественным следствием научно-технического прогресса и призваны облегчить нашу жизнь, сделать ее более комфортной и безопасной.

Возникает вопрос - как отграничить «опасные» для общества специальные технические устройства, оборот которых необходимо ограничить от «неопасных», которые не создают угрозу нарушения конституционных прав граждан? Данная грань весьма условна. Рассмотрим это на нескольких примерах.

Диктофон является техническим устройством, которое служит для получения и регистрации акустической информации. Размеры современных микрофонов, наличие специальных выносных и беспроводных микрофонов вполне позволяет использовать его негласно. Таким образом, диктофон, формально, обладает всеми признаками, присущими для категории «Специальные технические средства для негласного получения и регистрации акустической информации».

GPS-трекер это устройство приёма-передачи данных для спутникового контроля автомобилей, людей или других объектов, к которым оно прикрепляется, использующее GPS для точного определения местонахождения объекта. Таким образом, будучи размещенным в автомобиле, GPS-трекер позволит негласно для его владельца получать третьим лицам сведения о местонахождении автомобиля. Таким образом, по формальным признакам, указанное устройство относится к категории «Специальные технические средства для негласного контроля за перемещением транспортных средств и других объектов».

Однако все вышеописанное не значит, что диктофоны и GPS-трекеры сами по себе представляют угрозу нарушения конституционных прав человека. Диктофоны имеют вполне легальное применение - c их помощью, в частности, люди могут работать над своим произношением, готовиться к публичным выступлениям. Люди, которые опасаются за сохранность своих автомобилей, с помощью GPS-трекеров, в частности, могут в режиме реального времени получать сведения о местонахождении своего транспортного средств. Ограничение в обороте указанных предметов нецелесообразно и будет ограничивать естественный процесс научно-технического развития общества.

В то же время, существуют специальные технические средства, свободный оборот которых, безусловно, создает угрозу нарушения конституционных прав человека и гражданина. Трудно поспорить с тем, что код-грабберы, устройства для прослушивания телефонных переговоров не должны продаваться бесконтрольно.

C учетом вышеизложенного, представляется разумным говорить о наличии ряда условий, при одновременном наличии которых можно сделать вывод об отношении конкретного технического устройства к категории СТС НПИ.

\section{Baikal Research Journal}


Частично, об условиях относимости того или иного устройства к категории «специальные технические средства для негласного получения информации» сказано в Постановлении Конституционного Суда Российской «По делу о проверке конституционности части третьей статьи 138 Уголовного кодекса Российской Федерации в связи с жалобами граждан С.В. Капорина, И.В. Коршуна и других» от 31 марта 2011 г. № 3-П». Согласно Постановлению к таковым могут относиться технические средства, которые закамуфлированы под предметы (приборы) другого функционального назначения, в том числе бытовые; обнаружение которых в силу малогабаритности, закамуфлированности или технических параметров возможно только при помощи специальных устройств; которые обладают техническими характеристиками, параметрами или свойствами, обозначенными в соответствующих нормативных правовых актах; которые функционально предназначены для использования специальными субъектами.

Таким образом, проанализировав положения вышеуказанного Постановления, можно выделить группу признаков, по которым технические средства относятся к категории «специальных технических средств для негласного получения информации»:

1) закамуфлированность под предметы (приборы) другого функционального назначения, в том числе бытовые;

2) обнаружение устройства в силу малогабаритности, закамуфлированности или технических параметров возможно только при помощи специальных устройств;

3) устройство обладает техническими характеристиками, параметрами или свойствами, обозначенными в соответствующих нормативных правовых актах;

4) устройства функционально предназначены для использования специальными субъектами.

Закамуфлированность предполагает придание устройству внешней конструктивной схожести с предметами иного функционального назначения, в том числе с бытовыми предметами. Эти действия способствуют тайному, неочевидному получению информации.

Следует отметить, что в указанном выше Постановлении Конституционного Суда Российской Федерации отграничиваются СТС НПИ от бытовых предметов, без специальной доработки. В Постановлении об этом говорится: «Что касается технических средств (предметов, устройств), которые по своим техническим характеристикам, параметрам, свойствам или прямому функциональному предназначению рассчитаны лишь на бытовое использование массовым потребителем, то они не могут быть отнесены к специальным техническим средствам для негласного получения информации, если только им намеренно не приданы нужные качества и свойства, в том числе путем специальной технической доработки, программирования именно для неочевидного, скрытного их применения».

Действие указанного положения можно рассмотреть на следующем примере. В 2015 году сотрудниками отдела «К» ГУ МВД России по Иркутской области были выявлены признаки преступлений, предусмотренных ст.ст. 137, 138.1 УК РФ. Гражданин «Х» действуя с целью получения сведений о личной жизни своей бывшей супруги, под предлогом необходимости ремонта, вмонтировал в ее телевизор видеокамеру, внеся тем самым конструктивные изменения, позволяющие осуществлять негласное получение информации. После выявления указанного факта, в отношении гражданина «Х» было возбуждено уголовное дело, по признакам преступлений, предусмотренных ст.ст. 137, 138.1 УК РФ.

Указанный пример является показательным, если бы видеокамера была установлена на телевизоре, то она была бы заметна и несмотря на то что в этом со-

\section{Baikal Research Journal}


стоянии, видеокамера все равно могла бы фиксировать происходящее в комнате, признак негласного получения информации в этом случае отсутствовал бы.

Однако размещение в корпусе телевизора устройства, которое само по себе не относится к категории СТС НПИ (видеокамера), является частным случаем такого альтернативного варианта выполнения объективной стороны ст. 138.1 УК РФ как изготовление СТС НПИ.

Если обнаружение устройства в силу малогабаритности, закамуфлированности или технических параметров возможно только при помощи устройств, то это создает благоприятные условия для негласного (тайного, неочевидного) сбора информации. Очень распространены СТС для негласного получения акустической информации, представляющие собой пластину размерами 2 на 2 сантиметра, которая крепится на любую поверхность с помощью двустороннего скотча, позволяя при этом эффективно регистрировать и беспроводным способом передавать акустическую информацию в радиусе 12 метров. Конструктивные особенности указанных устройств, позволяют использовать их без ведома лиц, находящихся в помещении и обеспечивать эффективный сбор и передачу акустической информации. Обнаружить указанные устройства без применения специальной техники, способной фиксировать радиосигналы практически невозможно.

Такой признак как наличие у устройства технических характеристик, параметров или свойств, обозначенных в соответствующих нормативных правовых актах подразумевает соответствие требованиям, установленным главным образом двумя документами: Положению о ввозе в Российскую Федерацию и вывозе из Российской Федерации специальных технических средств, предназначенных для негласного получения информации, и списка видов специальных технических средств, предназначенных для негласного получения информации, ввоз и вывоз которых подлежат лицензированию ${ }^{2}$ и Положению о лицензировании деятельности физических и юридических лиц, не уполномоченных на осуществление оперативно-розыскной деятельности, связанной с разработкой, производством, реализацией, приобретением в целях продажи, ввоза в Российскую Федерацию и вывоза за ее пределы специальных технических средств, предназначенных (разработанных, приспособленных, запрограммированных) для негласного получения информации, и Перечня видов специальных технических средств, предназначенных (разработанных, приспособленных, запрограммированных) для негласного получения информации в процессе осуществления оперативно-розыскной деятельности ${ }^{3}$. В данных документах указаны основные категории специальных технических средств и некоторые технические подробности (уровень освещенности, расположение органов управления и др.

Такой признак как функциональное предназначение устройства для использования специальными субъектами предполагает то, что техническое устройство по

${ }^{2}$ Об утверждении Положения о ввозе в Российскую Федерацию и вывозе из Российской Федерации специальных технических средств, предназначенных для негласного получения информации, и списка видов специальных технических средств, предназначенных для негласного получения информации, ввоз и вывоз которых подлежат лицензированию : постановление Правительства РФ от 10.03.2000 г. № 214 : (в ред. от 08.12.2010) // СЗ РФ. 2000. № 12. Ст. 1292.

${ }^{3}$ Об утверждении Положения о лицензировании деятельности физических и юридических лиц, не уполномоченных на осуществление оперативно-розыскной деятельности, связанной с разработкой, производством, реализацией, приобретением в целях продажи, ввоза в Российскую Федерацию и вывоза за ее пределы специальных технических средств, предназначенных (разработанных, приспособленных, запрограммированных) для негласного получения информации, и Перечня видов специальных технических средств, предназначенных (разработанных, приспособленных, запрограммированных) для негласного получения информации в процессе осуществления оперативно-розыскной деятельности : постановление Правительства РФ от 01.07.1996 г. № 770 : (в ред. от 15.07.2002) // СЗ РФ. 1996. № 28. Ст. 3382.

\section{Baikal Research Journal}


своим характеристикам должно быть сопоставимо или лучше, чем аналогичные образцы, состоящие на вооружении государственных органов - субъектов оперативно-розыскной деятельности, указанных в ст. 13 Федерального закона «Об оперативно-розыскной деятельности» от 12 августа 1995 № 144-Ф34.

Несмотря на то, что в технически сложных устройствах функции записи видео являются не основными, а второстепенными, например, в телефоне, в продаже существуют специализированные технические устройства, предназначенные для негласного получения информации о каком-либо человеке [12]. Распространенные «бытовые» способы подслушивания с помощью граненого стакана или металлической кастрюли, по своей эффективности отличаются от применяемых в процессе оперативно-розыскной деятельности способов негласного получения звуковой информации, в силу чего не обладают общественной опасностью.

В связи с вышеизложенным, необходимо отграничивать деяния, формально содержащие признаки преступления, но не представляющие угрозы для личности, общества и государства (т.е. в соответствии с ч. 2 ст. 14 УК РФ не являющиеся преступлениями) от действий, причиняющих вред или создавших угрозу причинения вреда объекту уголовно-правовой охраны

Диспозиция статьи 138.1 УК РФ предусматривает ответственность за незаконные производство, приобретение и (или) сбыт специальных технических средств, предназначенных для негласного получения информации. При этом, объективная сторона может быть выражена только в активном действии, заключающемся в производстве, приобретении, сбыте вышеуказанных технических средств. По конструкции состав формальный, то есть момент окончания преступления совпадает с моментом окончания объективной стороны состава преступления.

Указанный набор альтернативных действий представляется неполным. В частности, представляется затруднительным дать правовую оценку действиям лица, которое приобрело устройство, конструктивно схожее с каким-либо бытовым предметом (например, с наручными часами), однако в процессе эксплуатации обнаружило в нем функции для негласного получения информации. В указанной ситуации, необходимо полагать, что приобретение данного устройства будет законным, так как на момент приобретения, лицо не осознавало, что в данном устройстве имеются функции для негласного получения информации. Кроме того, при необходимой внимательности и предусмотрительности не должно было и не могло предвидеть наступление общественно опасных последствий. В данной ситуации, интеллектуальное осознание факта обладания СТС НПИ возникает уже после фактического приобретения данного устройства, на стадии хранения, которая на данный момент не является уголовно-наказуемой, в связи с чем, данное лицо может законно владеть и пользоваться указанным имуществом.

Следует заострить внимание на изготовлении СТС НПИ как одном из альтернативных вариантов выполнения объективной стороны. С. П. Олефиренко [13] дал следующее определение незаконного производства: «разовое или серийное их изготовление любым способом».

В толковом словаре русского языка под редакцией С. И. Ожегова, слово «изготовить» является синонимом слов «сделать», «выработать». Слово «производить» указано синонимом слова «изготовить», «выработать». В связи с вышеизложенным, можно сделать вывод о том, что слова «изготовление» и «производство» в русском языке являются синонимами. Однако в уголовно-правовой доктрине этим понятиям придается различный оттенок.

${ }^{4}$ Об оперативно-розыскной деятельности : федер. закон от 12.08.1995 № 144-ФЗ : (в ред. от 29.06.) // СЗ РФ. 1995. № 33. Ст. 3349.

\section{Baikal Research Journal}

электронный научный журнал Байкальского государственного университета 
Позиция С.П. Олефиренко критиковалась М.С. Кривоногиным [12], который указывал на то, что единичный случай создания специального технического средства, предназначенного для негласного получения информации, не образует состав преступления.

Так, в Постановлении Пленума Верховного Суда РФ «О судебной практике по делам о преступлениях, связанных с наркотическими средствами, психотропными, сильнодействующими и ядовитыми веществами» ${ }^{5}$ под незаконным изготовлением наркотических средств, психотропных веществ или их аналогов без цели сбыта следует понимать совершенные в нарушение законодательства Российской Федерации умышленные действия, в результате которых из растений, содержащих наркотические средства или психотропные вещества, либо их частей, содержащих наркотические средства или психотропные вещества, лекарственных, химических и иных веществ получено одно или несколько готовых к использованию и потреблению наркотических средств, психотропных веществ или их аналогов.

В этом же Постановлении Пленума Верховного Суда РФ дается разъяснение понятию незаконное производство наркотических средств, психотропных веществ или их аналогов: «Совершенные в нарушение законодательства Российской Федерации умышленные действия, направленные на серийное получение таких средств или веществ из растений, химических и иных веществ (например, с использованием специального химического или иного оборудования, производство наркотических средств или психотропных веществ в приспособленном для этих целей помещении, изготовление наркотика партиями, в расфасованном виде».

Таким образом, в указанном постановлении под изготовлением понимается разовое, «кустарное» создание, а под производством - создание серийное, с использованием специального оборудования, в специальном помещении, то есть более организованное и налаженное.

В Постановление Пленума Верховного Суда РФ «О судебной практике по делам о хищении, вымогательстве и незаконном обороте оружия, боеприпасов, взрывчатых веществ и взрывных устройств» ${ }^{6}$ от под незаконным изготовлением огнестрельного оружия и его основных частей, огнестрельного оружия ограниченного поражения, газового, холодного оружия, метательного оружия, боеприпасов, патронов, взрывчатых веществ или взрывных устройств, патронов к огнестрельному оружию ограниченного поражения либо газовому оружию, влекущим уголовную ответственность, понимается: «их создание, в тол числе путел переделки каких-либо иных предлетов (например, ракетниц, пневматических, стартовых и строительно-монтажных пистолетов, предметов бытового назначения или спортивного инвентаря), без полученной в установленном порядке лицензии, в результате чего они приобретают свойства огнестрельного, газового или холодного оружия, боеприпасов, взрывчатых веществ или взрывных устройств» .

В указанном Постановлении Пленума понятия «изготовление» и «производство» тождественны. Несмотря на то, что по смыслу переделка оружия подразумевает собой наличие специального оборудования, она все равно входит в понятие «изготовление».

Отсутствие в уголовно-правовой теории единого подхода $\kappa$ пониманию терминов «производство» и «изготовление» приводит к их неоднозначному толко-

${ }^{5}$ О судебной практике по делам о преступлениях, связанных с наркотическими средствами, психотропными, сильнодействующими и ядовитыми веществами : постановление Пленума ВС РФ от 15.06.2006 г. № 14 : (в ред. от 30.06.2015) // Бюллетень ВС РФ. 2006. № 8.

${ }^{6}$ О судебной практике по делам о хищении, вымогательстве и незаконном обороте оружия, боеприпасов, взрывчатых веществ и взрывных устройств : постановление Пленума ВС РФ от 12.03.2002 г. № 5 : (в ред. от 03.12.2013) // Бюллетень ВС РФ. 2002. № 5.

\section{Baikal Research Journal}


ванию. Если придерживаться позиции Постановления Пленума Верховного Суда РФ «О судебной практике по делам о хищении, вымогательстве и незаконном обороте оружия, боеприпасов, взрывчатых веществ и взрывных устройств», то лицо, однократно изготовившее СТС НПИ, подлежит уголовной ответственности, а если придерживаться позиции Постановления Пленума Верховного Суда РФ «О судебной практике по делам о преступлениях, связанных с наркотическими средствами, психотропными, сильнодействующими и ядовитыми веществами», то лицо однократно изготовившее СТС НПИ уголовной ответственности не подлежит, так как имеет место не предусмотренное диспозицией статьи изготовление, а не производство.

Справедливо полагать, что даже однократное изготовление СТС НПИ, предназначенного, например, для прослушивания телефонных переговоров, безусловно, обладает общественной опасностью и должно преследоваться в уголовном порядке.

Если следовать устоявшейся логике законодателя (в частности, на примере конструирования статей УК РФ, предусматривающих уголовную ответственность за незаконный оборот наркотических средств, психотропных веществ и за незаконный оборот оружия), то в число альтернативных действий, указанных в диспозиции статьи, необходимо включить: изготовление, хранение, перевозку и пересылку СТС НПИ. Пренебрежение указанными элементами незаконного оборота может снизить эффективность уголовно-правовой охраны общественных отношений в сфере конституционных прав на тайну переписки, телефонных переговоров, почтовых, телеграфных или иных сообщений.

Субъект преступления в данной статье - общий, ответственность наступает с шестнадцати лет.

Субъективная сторона преступления представлена только в виде прямого умысла. Цель, мотив и эмоции на квалификацию деяния не влияют. Но при этом, важным признаком умышленной формы вины является осознание общественной опасности деяния как интеллектуальный момент умысла [14].

Представляется, что дальнейшее совершенствование уголовно-правового противодействия незаконному обороту СТС НПИ заключается в дифференциации уголовной ответственности путем выделения квалифицированных составов указанного преступления в отдельные части. Данная мера позволит разграничить по степени общественной опасности различные виды указанного преступления и установить каждому соответствующий размер наказания.

Ряд разновидностей данных преступлений, например, сбыт СТС НПИ, совершенный с использованием должностного положения, производство СТС НПИ в крупных масштабах отличаются повышенной общественной опасностью, и мера ответственности за такие деяния должна быть более строгой, чем, например, за приобретение видеоручки.

Резюмируя вышесказанное, хотелось бы кратко озвучить предложения по совершенствованию механизма уголовно-правового регулирования оборота специальных технических средств для негласного получения информации.

Существующие проблемы правоприменительной практики по делам о преступлениях, предусмотренных ст. 138.1 УК РФ, на наш взгляд, необходимо разрешить путем принятия соответствующего Постановления Пленума Верхового Суда РФ. Принятие данного судебного акта позволит выработать единый подход к определению предмета преступления, вариантам выполнения объективной стороны и решить ряд других вопросов, возникающих при реализации ст. 138.1 УК РФ.

Текст статьи 138.1 УК РФ должен быть дополнен иными вариантами выполнения объективной стороны, в частности такими, как «использование», «хранение». Указанные дополнения позволят ликвидировать парадокс, когда приобре-

\section{Baikal Research Journal}


тенный предмет, который ограничен в свободном обороте, можно использовать безо всяких юридических последствий.

Кроме прочего, необходимо разрешить вопрос с подходом к пониманию используемого в статье термина «производство». На наш взгляд, это можно сделать двумя путями: либо дополнить текст статьи таким вариантом выполнения объективной стороны как «изготовление», либо в соответствующем Постановлении Пленума Верховного суда РФ дать разъяснение понятию «производство» применительно к статье 138.1 УК РФ.

Бурный темп научно-технического прогресса обуславливает необходимость быстро и оперативно реагировать на возникающие угрозы. Уголовно-правовая политика в сфере незаконного оборота специальных технических средств для негласного получения информации должна не столько стремиться «загнать в рамки» существующие общественные отношения, сколько работать на упреждение и максимально эффективно и гибко минимизировать незаконный оборот СТС НПИ.

\section{Список использованной литературы}

1. Асанова И. П. Современное состояние российского уголовного законодательства о незаконном обороте специальных технических средств / И. П. Асанова // Вестник экономики, права и социологии. - 2016. - № 1. - С. 102-105.

2. Нуркаева Т. Н. Личные (гражданские) права и свободы человека и их охрана уголовно-правовыми средствами: вопросы теории и практики / Т. Н. Нуркаева. - СПб. : Юрид. центр Пресс, 2003. - 254 с.

3. Уголовное право России. Особенная часть : учебник / под ред. Ф. Р. Сундурова, М. В. Талан. - М. : Статут, 2012. - 943 с.

4. Уголовное право Российской Федерации. Особенная часть : учебник / под ред. Л. В. Иногамовой-Хегай, А. И. Рарога, А. И. Чучаева. - М. : ИНФРА-М : КОНТРАКТ, 2011. - 793 с.

5. Комментарий к Уголовному кодексу Российской Федерации / под ред. А. В. Бриллиантова. - М. : Проспект, 2010. - 1391 с.

6. Подгорная Н. В. К вопросу непосредственного объекта незаконного оборота специальных технических средств, предназначенных для негласного получения информации / Н. В. Подгорная // Актуальные проблемы уголовной и уголовно-процессуальной политики Российской Федерации : материалы всерос. науч.-практ. конф. - Омск : Омская юридическая академия, 2014. - С. 82-86.

7. Устинова Т. Нарушение тайны переписки, телефонных и иных сообщений граждан / Т. Устинова // Уголовное право. - 1998. - № 2. - С. 6-11.

8. Новиков В. А. Незаконный оборот специальных технических средств, предназначенных для негласного получения информации: объект преступления и место в системе особенной части УК РФ / В. А. Новиков // Расследование преступлений: проблемы и пути их решения. -2015 . - № 2 (8). - С. 56-58.

9. Родивилина В. А. Особенности квалификации преступлений в сфере незаконного оборота специальных технических средств, предназначенных для негласного получения информации / В. А. Родивилина, И. П. Родивилин // Вестник Восточно-Сибирского института МВД России. - 2013. - № 3 (66). - С. 61-66.

10. Радченко О. В. Проблемы квалификации незаконного оборота специальных технических средств, предназначенных для негласного получения информации / О. В. Радченко, С. В. Габеев // Вестник Восточно-Сибирского института МВД России. - 2014. - № 3. C. $26-33$.

11. Петроченков С. Д. Незаконный оборот специальных технических средств, предназначенных для негласного получения информации: законодательный подход и судебная практика / С. Д Петроченков // Пробелы в российском законодательстве. - 2012. № 3. - C. $155-157$.

12. Кривоногин М. С. Незаконный оборот специальных технических средств: проблемы квалификации преступлений / М. С. Кривоногин // Исторические, философские, по-

\section{Baikal Research Journal}


литические и юридические науки, культурология и искусствоведение. Вопросы теории и практики. - 2014. - № 2-2. - С. 110-112.

13. Олиференко С. П. Уголовно-правовые исследования состояния морального вреда в преступлениях, предусмотренных статьями 138, 138.1 УК РФ / С. П. Олиференко // Вестник Челябинского государственного университета. Серия: Право. - 2013. — № 5. — С. 90-94.

14. Кузнецов В. И. Уголовно-правовое противодействие корыстной преступности. В 2 ч. : учеб. пособие / В. И. Кузнецов. - Иркутск : Изд-во ИГУ, 2015. - Ч. 1. -233 с.

\section{References}

1. Asanova I. P. Current state of Russian criminal law on illegal trafficking of special technical equipment. Vestnik ekonomiki, prava $i$ sotsiologii = The Review of Economy, the Law and Sociology, 2016, no. 1, pp. 102-105. (In Russian).

2. Nurkaeva T. N. Lichnye (grazhdanskie) prava $i$ svobody cheloveka $i$ ikh okhrana ugolovno-pravovymi sredstvami: voprosy teorii i praktiki [Personal (civil) human rights and freedom and their protection by criminal means: Theory and Practice]. Saint Petersburg, Juridichesky center Press Publ., 2003. 254 p.

3. Sundurov F. R., Talan M. V. (eds). Ugolovnoe pravo Rossii. Osobennaya chast' [Russian Criminal Law. Special Part]. Moscow, Statut Publ., 2012. 943 p.

4. Inogamova-Khegai L. V., Rarog A. I., Chuchaev A. I. (eds). Ugolovnoe pravo Rossijskoj Federacii. Osobennaya chast' [Criminal law of the Russian Federation. Special Part]. Moscow, INFRA-M, KONTRAKT, 2011. $793 \mathrm{p}$.

5. Brilliantov A. V. (ed.). Kommentarii k Ugolovnomu kodeksu Rossiiskoi Federatsii. [Comments to the Criminal Code of the Russian Federation]. Moscow, Prospekt Publ., 1391 p.

6. Podgornaya N. V. On the issue of direct object of illegal turnover of special technical means intended for surreptitious obtaining of information. Aktual'nye problemy ugolovnoi i ugolovno-protsessual'noi politiki Rossiiskoi Federatsii. Materialy vserossiiskoi nauchno-prakticheskoi konferentsii [Practical problems of criminal and criminal-procedural policy of the Russian Federation. Materials of the All-Russian Scientific and Practical Conference]. Omsk, Omsk law Academy Publ., 2014. pp. 82-86. (In Russian).

7. Ustinova T. Violation of the secrecy of correspondence, telephone and other communications of citizens. Ugolovnoe pravo = Criminal law, 1998, no. 2,- pp. 6-11. (In Russian).

8. Novikov V. A. Illegal turnover of special technical means intended for surreptitious obtaining of information: object of crime and place in system of special part of the Criminal Code of the Russian Federation. Rassledovanie prestuplenii: problemy i puti ikh resheniya [Investigation of crimes: problems and ways to solve them]. 2015, no. 2 (8), pp. 56-58. (In Russian).

9. Rodivilina V. A., Rodivilin I. P. Features of crime qualification in the sphere of illegal turnover of special technical means intended for surreptitious obtaining of information. Vestnik Vostochno-Sibirskogo instituta MVD Rossii = Vestnik of the Eastern Siberia Institute of the Ministry of the Interior of the Russian Federation, 2013, no. 3 (66), pp. 61-66. (In Russian).

10. Radchenko O. V., Gabeev S. V. Problems of illegal turnover qualification of special technical means intended for surreptitious obtaining of information. Vestnik Vostochno-Sibirskogo instituta MVD Rossii = Vestnik of the Eastern Siberia Institute of the Ministry of the Interior of the Russian Federation, 2014, no. 3, pp. 26-33. (In Russian).

11. Petrochenkov S. D. Illegal turnover of special technical means intended for surreptitious obtaining of information: legislative approach and judicial practice. Probely $v$ rossiiskom zakonodatel'stve = Gaps in Russian legislation, 2012, no. 3, pp. 155-157. (In Russian).

12. Krivonogin M. S. Illegal turnover of special technical means: problems of crime qualification. Istoricheskie, filosofskie, politicheskie $i$ yuridicheskie nauki, kul'turologiya i iskusstvovedenie. Voprosy teorii $i$ praktiki = Historical, Philosophical, Political and Law Sciences, Culturology and Study of Art. Issues of Theory and Practice, 2014, no. 2-2, pp. 110-112.

13. Oliferenko S. P. Criminal-legal research of a moral harm state in crimes provided by articles 138, 138.1 of the Criminal Code of the Russian Federation. Vestnik Chelyabinskogo gosudarstvennogo universiteta. Seriya: Pravo = Bulletin of Chelyabinsk State University. Series: Law, 2013, no. 5, pp. 90-94.

14. Kuznetsov V. I. Ugolovno-pravovoe protivodeistvie korystnoi prestupnosti [Criminallegal counteraction of mercenary criminality]. Irkutsk State University Publ., 2015, vol. 1. $233 \mathrm{p}$.

\section{Baikal Research Journal}




\section{Информация об авторе}

Усов Евгений Геннадьевич - адъюнкт, Восточно-Сибирский институт МВД России, 664039, г. Иркутск, ул. Лермонтова 110, e-mail: usov.evgeniy@list.ru.

\section{Author}

Evgeny G. Usov - Adjunct, East Siberian Institute of MIA of Russia, 110 Lermontov St., 664039, Irkutsk, e-mail: usov.evgeniy@list.ru.

\section{Для цитирования}

Усов Е. Г. К вопросу о квалификации преступления, предусмотренного ст. 138.1 УК РФ/ Е.Г. Усов // Baikal Research Journal. — 2018. - T. 9, № 1. — DOI : 10.17150/24116262.2018.9(1).19.

\section{For Citation}

Usov E. G. On the Issue of Crime Qualification under Art. 138.1 of the Criminal Code of the Russian Federation. Baikal Research Journal, 2018, vol. 9, no. 1. DOI: 10.17150/24116262.2018.9(1).19. (In Russian).

\section{Baikal Research Journal}

